CONF- $9507200--1$

UCRL-JC-120405

PREPRINT

\title{
Chemical Kinetic Modelling of Hydrocarbon Ignition
}

\section{RECEIVED}

\author{
C. K. Westbrook, W. J. Pitz, H. J. Curran, NOV 171995 \\ P. Gaffuri, and N. M. Marinov \\ OSTI
}

This paper was prepared for submittal to the International Symposium on Gas Phase Chemical Reaction Systems: Experiments and Models 100 years after Max Bodenstein

Heidelberg, Germany

July 26-28, 1995

August 25, 1995

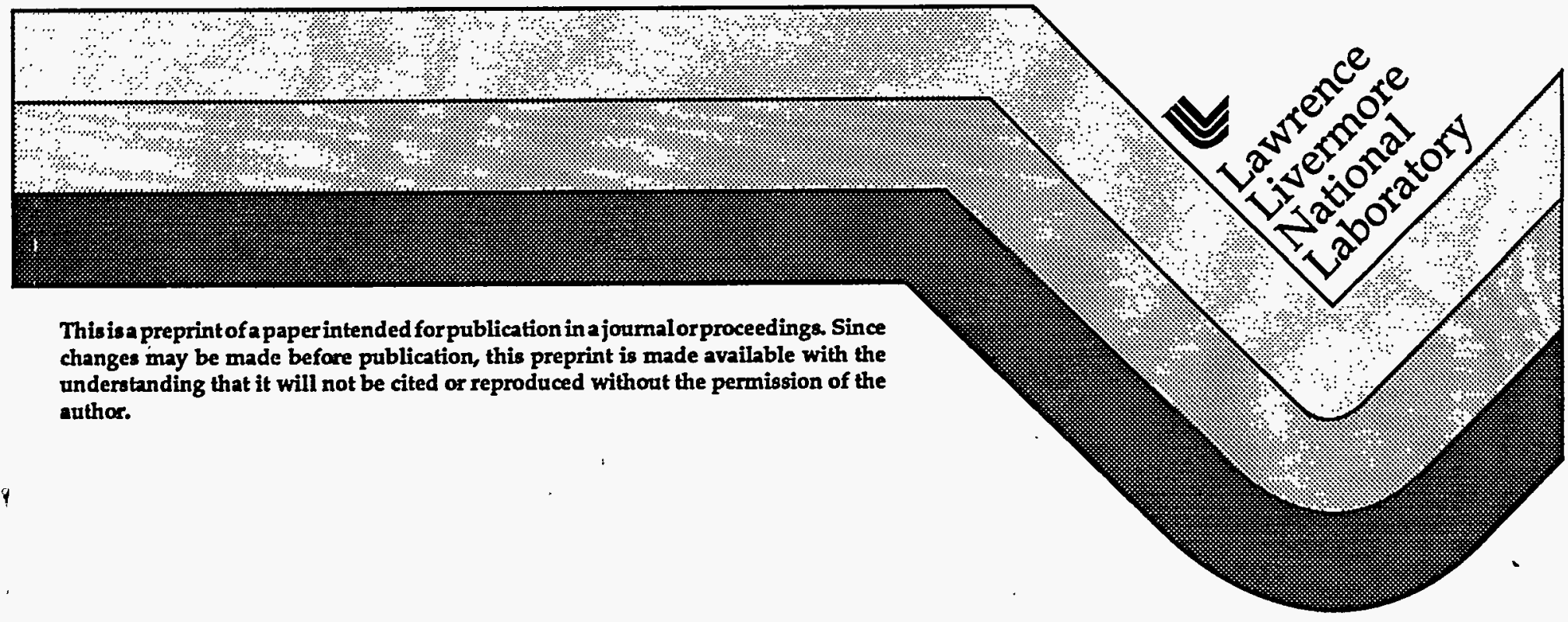


This document was prepared as an account of work sponsored by an agency of the United States Government. Neither the United States Government nor the

$\because$ University of California nor any of their employees, makes any warranty, express or implied, or assumes any legal liability or responsibility for the accuracy, completeness, or usefulness of any information, apparatus, product, or process disclosed, or represents that its use would not infringe privately owned rights. Reference herein to any specific commercial product, process, or service by trade name, trademark, manufacturer, or otherwise, does not necessarily constitute or imply its endorsement, recommendation, or favoring by the United States Government or the University of California. The views and opinions of authors expressed herein do not necessarily state or reflect those of the United States Government or the University of California, and shall not be used for advertising or product endorsement purposes. 


\title{
Chemical Kinetic Modelling of Hydrocarbon Ignition
}

\author{
Charles K. Westbrook \\ William J. Pitz \\ Henry J. Curran \\ Paolo Gaffuri \\ Nick M. Marinov \\ Lawrence Livermore National Laboratory . \\ P. O. Box 808, Livermore, CA 94550 USA
}

\begin{abstract}
Chemical kinetic modeling of hydrocarbon ignition is discussed with reference to a range of experimental configurations, including shock tubes, detonations, pulse combustors, static reactors, stirred reactors and internal combustion engines. Important conditions of temperature, pressure or other factors are examined to determine the main chemical reaction sequences responsible for chain branching and ignition, and kinetic factors which can alter the rate of ignition are identified.
\end{abstract}

\section{Introduction}

Ignition of hydrocarbon combustion takes many forms in laboratory-scale and practical systems ranging from shock tubes to internal combustion engines. For example, in spark-ignited automotive engines, two vastly different types of ignition problems constantly compete against each other, the spark plug must ignite the reactive mixture reliably and repeatably in order for the engine to produce power, while ignition of the end-gases (the last portion of reactive mixture to be consumed by the flame in the combustion chamber) can produce knocking behavior with potential to destroy the engine. High efficiency, low polluting pulse combustion systems, used for home space heating, industial processing and propulsion, are controlled almost entirely by the periodic ignition of fresh fuel and oxidizer by mixing with hot product gases. This ignition process involves a crucial interaction between ignition and resonant pressure oscillations in the combustion chamber, and if the ignition and pressure wave are not properly in phase with each other, the pulse combustor will not operate.

Hydrocarbon ignition usually involves complex interactions between physical and chemical factors, and it therefore is a suitable and often productive subject for computer simulations. In most of the studies to be discussed below, the focus of the attention is placed on the chemical features of the system. The other physical parts of each application are generally included in the form of initial or boundary conditions to the chemical kinetic parts of the problem, as appropriate for each type of application being addressed.

\section{General Features of Ignition}

Ignition in combustion systems consists of enabling the combustible medium to increase or sustain its rate of chemical reaction and heat release. Every different combustion system operates under its own conditions involving energy loss mechanisms, transport mechanisms for energy and mass, and many other properties, and therefore the meaning of ignition will vary widely depending on what system is being considered. In many situations, ignition will result in steady combustion such as ignition of a laminar burner flame, while in other cases it will result in transient and violent behavior such as explosion. The subject of ignition is suitable for entire volumes, and the present discussion is sharply focused on purely chemical kinetic elements; the book by Glassman [1] includes a very nice discussion of many of the additional concepts important to ignition for further study. For the purposes of the present discussion, ignition consists of a rapid growth in the radical pool of a chemically reactive mixture which may be entirely gaseous or may include fuel droplets or particles. This growth rate must be sufficient to overcome any appropriate loss mechanisms which may apply to the system in question. While the material below will emphasize the chemical kinetic features of these systems, other processes are occurring which will be noted and must be considered in more 


\section{Chemical Kinetic Reaction Mechanisms}

Development of detailed chemical kinetic reaction mechanisms is a very large subject area, combining theory, experiment and computer studies. Many of the experimental studies consist of carefully focused work that isolates one reaction at a time, while other experiments provide information on collections of large numbers of reactions and chemical species. The product of these studies is generally an interconnected set of thermochemical data, reaction rate expressions, chemical species data, and often data on transport properties. In many cases the numerical model and solution algorithms are intricately connected to the reaction mechanism as well. These reaction mechanisms are generally developed by beginning with the simplest and most fundamental blocks [2,3], usually the submechanism for $\mathrm{H}_{2}$ oxidation, followed by the mechanisms for $\mathrm{CO}$, methane, methanol, ethane and continuing as far as the application demands. These mechanisms are then tested extensively through comparisons with experimental data. The most useful such mechanisms are validated by comparisons with data from as wide as possible a range of operating conditions and types of environments. Thus, a mechanism would use data from shock tubes, flow reactors, laminar flames, and many other types of experiments to test its generality and validity. Examples of reaction mechanisms in the recent literature which have been developed and tested in this way can be found in the literature cited [4-8].

The most important elements in such reaction mechanisms are the steps which affect the population (or pool) of reactive radical species. Below, the role which these reactions play in determining practical features of ignition will be outlined.

\section{High Temperature Ignition}

At temperatures above about $1200 \mathrm{~K}$, hydrocarbon reaction mechanisms are simplified by the fact that alkyl radicals react primarily by means of $\beta$-decomposition. Thus the complex sequence (discussed below) of reactions initiated by addition of molecular oxygen to alkyl radicals

$$
\mathrm{R}+\mathrm{O}_{2}=\mathrm{RO}_{2}
$$

does not influence the overall process of ignition. Identification of the chain branching sequences is also very much simplified. For example, $\mathrm{H}$ atom abstraction from fuel molecules $\mathrm{RH}$ by $\mathrm{O}$ atoms leads to chain branching

$$
\mathrm{RH}+\mathrm{O}=\mathrm{R}+\mathrm{OH}
$$

because it consumes one $O$ radical and produces two radicals $R$ and $O H$. In actual practice, chain branching from $O$ atom reactions is not often especially important. However, these reactions can be important in applications where the oxidizer directly produces $\mathrm{O}$ atoms, such as when the oxidizer is something like $\mathrm{N}_{2} \mathrm{O}, \mathrm{NO}_{2}$ or ozone [3]. This can also explain the rapid ignition of fuels such as nitrohexane or hexyl nitrate, where decomposition of the fuel produces $\mathrm{NO}_{2}$ radicals which then decompose further to produce $\mathrm{O}$ atoms in large quantities [9]. For example, a compound referred to as "diesel ignition improver" is ethyl-hexyl nitrate, which rapidly releases $O$ atoms into the reactive gas mixture and accelerates ignition by enhancing Reaction (2) above.

However, $\mathrm{O}$ atoms are not often present in large quantities under most practical ignition conditions, and other reaction sequences are usually more important in determining ignition rates. Under most normal combustion conditions, the most important chain branching reaction is the reaction of $\mathrm{H}$ atoms with molecular oxygen $[2,3]$. consuming one $\mathrm{H}$ atom radical to produce two radicals

$$
\mathrm{H}+\mathrm{O}_{2}=\mathrm{O}+\mathrm{OH}
$$

In many practical application environments, the overall rate of combustion or ignition can easily be understood in terms of this reaction. Processes or reactions which increase the $\mathrm{H}$ atom concentration will accelerate the rate of combustion and enhance ignition, while processes which consume $\mathrm{H}$ atoms or remove $\mathrm{H}$ atoms from the radical pool retard ignition. One example of this is the observation that increased pressure retards both ignition and flame propagation [10]. The explanation for this trend is the contribution of a competing reaction

$$
\mathrm{H}+\mathrm{O}_{2}+\mathrm{M}=\mathrm{HO}_{2}+\mathrm{M}
$$

which competes with Reaction (3) but does not increase the radical pool or lead to chain branching. The rate of reaction (4) increases with pressure relative to the rate of reaction (3), so the rate of chain branching from reaction (3) is effectively 
reduced by increasing pressure. As discussed below, there are a variety of other chemical effects which provide either competition with reaction (3) to inhibit ignition or provide additional $\mathrm{H}$ atoms to promote ignition, and both effects are due to the chain branching nature of reaction (3).

\section{4,1 Hydrocarbon Ignition in Shock Tubes}

An example of the influence that $\mathrm{H}$ atom production has on shock tube ignition is illustrated in Figure 1, showing ignition delay time for several alkanes as a function of temperature behind reflected shock waves. The experiments were carried out by Burcat et al. [11] and the kinetic modeling was done by Westbrook and Pitz [12]. Note that no experiments were carried out for $\mathrm{iC}_{4} \mathrm{H}_{10}$; the results for isobutane in Fig. 1 are computational results only. Ignition delay times for methane are much longer than for the other fuels and the ignition delay times for all of the larger $n-$

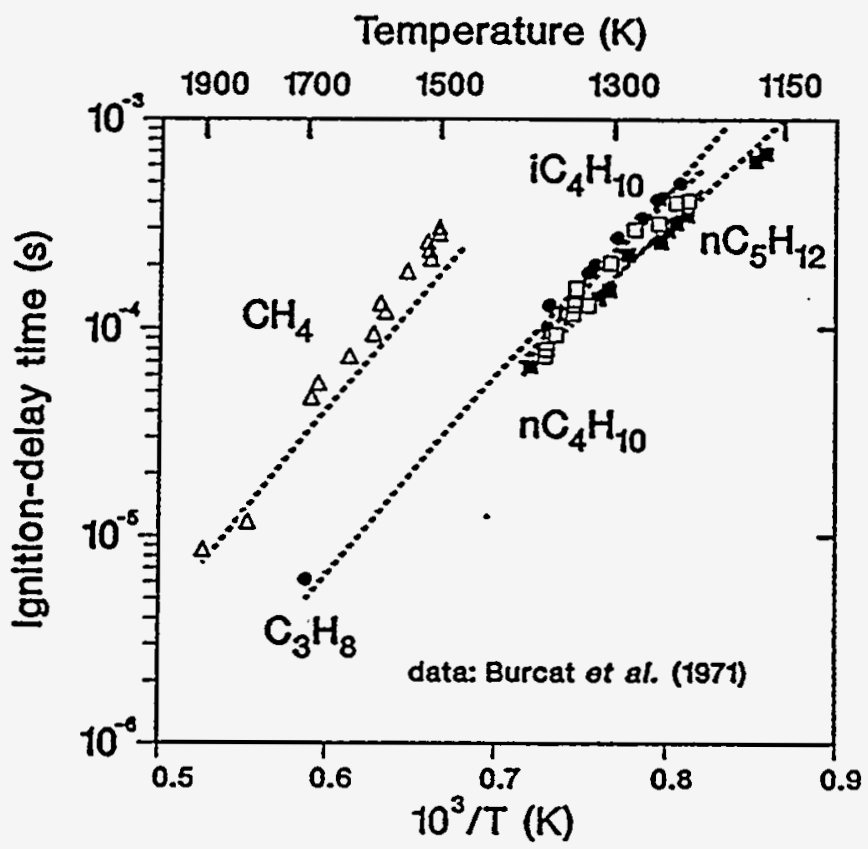

Figure 1. Experimental shock tube ignition delay time measurements (symbols) and model predictions for methane, propane, n-butane and n-pentane. Also shown are computed predictions for iso-butane.

alkanes are approximately equal. Although not shown, ignition delay times for ethane are significantly shorter than for the larger fuels. The model results are in good agreement with the measurements, and the calculations show that the differences between these similar fuels can be best understood in terms of their relative chain branching rates and especially the production of $\mathrm{H}$ atoms from the different fuels. Specifically, $H$ atom abstraction from methane produces methyl radicals, which are either oxidized to produce formaldehyde or recombine to produce ethane. Production of ethane results in chain termination due to removal of methyl radicals from the radical pool, not branching. Therefore, the major alkyl radical produced from methane leads not to chain branching but primarily to chain termination. In the case of ethane, the only alkyl radical produced by ethane is the ethyl $\left(\mathrm{C}_{2} \mathrm{H}_{5}\right)$ radical; $\beta$-decomposition of ethyl radicals produces $\mathrm{H}$ atoms via

$$
\mathrm{C}_{2} \mathrm{H}_{5}(+\mathrm{M})=\mathrm{C}_{2} \mathrm{H}_{4}+\mathrm{H}(+\mathrm{M})
$$

Therefore, all $\mathrm{H}$ atom abstraction reactions from ethane lead to ethyl radicals, and the most important subsequent reaction of ethyl radicals produces $\mathrm{H}$ atoms, which under these conditions provide chain branching via reaction (3) with $\mathrm{O}_{2}$. All of the other alkane fuels produce two or more alkyl radicals from $\mathrm{H}$ atom abstraction reactions, and some of these alkyl radicals produce $\mathrm{H}$ atoms while others produce 
methyl radicals. For example, propane $\left(\mathrm{C}_{3} \mathrm{H}_{8}\right)$ produces $\mathrm{i}-\mathrm{C}_{3} \mathrm{H}_{7}$ and $\mathrm{n}-\mathrm{C}_{3} \mathrm{H}_{7}$

radicals and $n$-pentane $\left(\mathrm{C}_{5} \mathrm{H}_{12}\right)$ produces three pentyl radicals, leading to:

$$
\begin{aligned}
\mathrm{C}_{3} \mathrm{H}_{8} & \Rightarrow \mathrm{i}-\mathrm{C}_{3} \mathrm{H}_{7}=\mathrm{C}_{3} \mathrm{H}_{6}+\mathrm{H} \\
& \Rightarrow \mathrm{n}-\mathrm{C}_{3} \mathrm{H}_{7}=\mathrm{C}_{2} \mathrm{H}_{4}+\mathrm{CH}_{3} \\
\mathrm{n}-\mathrm{C}_{5} \mathrm{H}_{12} & \Rightarrow 1-\mathrm{C}_{5} \mathrm{H}_{11}=\mathrm{C}_{2} \mathrm{H}_{4}+\mathrm{C}_{2} \mathrm{H}_{4}+\mathrm{CH}_{3} \\
& \Rightarrow 2-\mathrm{C}_{5} \mathrm{H}_{11}=\mathrm{C}_{3} \mathrm{H}_{6}+\mathrm{C}_{2} \mathrm{H}_{4}+\mathrm{H} \\
& \Rightarrow 3-\mathrm{C}_{5} \mathrm{H}_{11}=1 \mathrm{C}_{4} \mathrm{H}_{8}+\mathrm{CH}_{3}
\end{aligned}
$$

Thus $\mathrm{H}$ atom abstraction from alkane fuels larger than ethane, followed by $\beta$-decomposition leads to a mixture of chain branching and chain termination reactions. The rate of ignition is then seen to be fastest for ethane, with all of the $\beta$-decomposition reactions producing chain branching, followed by the larger alkanes with mixtures of chain branching and termination, followed by methane, the slowest to ignite since only methyl radicals are produced. It must not be forgotten that these alkyl radicals can participate in additional reactions not shown here, so the discussion above represents only the major reaction paths. However, under shock tube conditions, these represent the most significant reaction paths and the overall analysis of the relative rates of ignition in these terms is generally accurate. Most numerical models of shock tabe ignition consider the ignition to occur at either constant volume in the case of reflected shock waves or at constant pressure for incident shock waves. Of course, both of these are idealizations and, like corrections for boundary layers and other nonideal conditions, their effects and appropriateness must be considered in the modeling analysis." .

\section{4,2 Hydrocarbon Ignition in Detonations}

Chemical kinetics of high temperature ignition plays a key role in the propagation of detonations. Ignition behind the shock wave in a detonation must be rapid enough for the reactive heat release of the combustible gases to reinforce the shock wave. Kinetic modeling has been valuable in the analysis of detonation phenomena, ranging from full CFD simulations with chemical kinetics [13] to studies using the ZND model [14], which uses kinetic models to calculate characteristic ignition delay times and relate these time scales to properties such as the detonation cell size, critical detonation initiation energy, and critical tube diameter. Most kinetic models of ignition in detonation waves are considered to be adiabatic and constant volume calculations, similar to conditions in reflected shock wave simulations.

The same type of chain branching/chain termination analysis used above for the shock tube applies equally to kinetic analyses of detonations. In particular, modifications in operating conditions that reduce the rate of chain branching will result in longer ignition delay times, which lead to larger detonation cell sizes and greater critical energy for detonation initiation. Eventually, if the ignition delay time becomes sufficiently long, a detonation may eventually no longer be possible for a given fuel/oxidizer mixture. An excellent example of this feature is provided by the effect of adding diluents or chemical inhibitors to otherwise detonable mixtures. If halogenated species such as $\mathrm{HBr}, \mathrm{CH}_{3} \mathrm{Br}, \mathrm{CF}_{3} \mathrm{Br}$, or others are added to detonable hydrocarbon/air or hydrocarbon/oxygen mixtures, they are found [15] to increase detonation cell sizes, and if enough inhibitor is added, the detonation eventually is extinguished. Kinetic modeling [15] shows that the halogenated inhibitors lead to reaction sequences which catalytically remove radical species from the radical pool. For example, if $\mathrm{HBr}$ is the additive, the following reactions are important:

$$
\begin{aligned}
& \mathrm{HBr}+\mathrm{H}=\mathrm{H}_{2}+\mathrm{Br} \\
& \mathrm{H}+\mathrm{Br}_{2}=\mathrm{HBr}+\mathrm{Br} \\
& \mathrm{Br}+\mathrm{Br}+\mathrm{M}=\mathrm{Br}_{2}+\mathrm{M}
\end{aligned}
$$

The overall sum of these reactions is the net reaction $\mathrm{H}+\mathrm{H}=\mathrm{H}_{2}$. It is interesting to note that this is exactly the same reaction set first analyzed 100 years ago by Max Bodenstein [16], whose work is being recognized in this Symposium. Removal of $\mathrm{H}$ atoms is especially important, since as noted above, these $\mathrm{H}$ atoms cannot then participate in chain branching through reaction (3). The same processes have been shown [17] to inhibit and extinguish flame propagation through their catalytic activity in providing chain termination and $\mathrm{H}$ atom removal from the radical pool. 


\subsection{Hydrocarbon Ignition in Pulse Combustors}

A third example of the role of kinetic modeling in the analysis of practical combustion systems at high temperatures is in simulations of pulse combustion. Pulse combustors have been used for many years in propulsion, industrial processes such as drying, and in home furnaces, where they are valued for their thermal efficiency and low $\mathrm{NO}_{\mathrm{x}}$ production rates. However, until kinetic modeling was used to analyze the role of thermal ignition in these systems, it had been impossible to understand the principles of pulse combustion and the real reasons for their good pefformance. These studies by Keller and Barr et al. [18-20] showed that, in contrast with ignition in shock tubes and detonations, faster ignition did not necessarily lead to enhanced system performance. Instead, the key to pulse combustion is that the periodic ignition of the fuel/oxidizer mixture should occur in phase with the resonant pressure oscillations in the combustion chamber, following Rayleigh's criterion. Enhanced system performance may sometimes require that ignition be accelerated, but in other cases it may be necessary to retard hydrocarbon fuel ignition to improve the system performance. These observations were made in systems fueled by natural gas and methane [18], in which the fuel/air ignition occurred slightly earlier than the peak in the system pressure. Kinetic modeling indicated that system performance could be improved if ignition could be retarded, and this could be accomplished by adding an inert diluent such as $\mathrm{CO}_{2}$ or $\mathrm{N}_{2}$, or by decreasing the percentage of ethane in the natural gas, predictions that were then verified by direct experimental measurements.

The kinetic simulations of the pulse combustor ignition can be carried out under conditions which closely approximate those in a continuously stirred tank reactor (cstr). In those calculations, hot product gases are steadily mixed with cold, unburned reactants until the mixtures ignite. The reaction mechanisms used are valid for high temperatures, and the most important, sensitive reaction is reaction (3), and the combined influences of chemical kinetics, acoustics, and fluid dynamics can all be incorporated into a coherent practical design model [20].

Practical ignition systems can also operate at temperatures much higher than those discussed here. Spark plug ignition in automobile engines or plasma jet or torch ignition are examples of systems where, at least for a brief period of time, temperatures are sufficiently high to ionize the reactive gases. In many situations, the period of time when plasma effects prevail is very short, and the gas temperatures rapidly fall into the regime where the above comments on high temperature ignition apply. The general subject of plasma/kinetics interactions is outside the scope of the present paper, but the principle of identifying the major chain branching sequences that lead to ignition is still certainly valid.

\section{Intermediate Temperature Ignition}

At intermediate system temperatures, different reaction sequences lead to chain branching. The activation energy of reaction (3) is quite high $(-17 \mathrm{kcal} / \mathrm{mol})$, so when the temperature falls below about $1000 \mathrm{~K}$, its rate becomes quite slow. Instead, reaction (4) is most important, since it has almost no temperature dependence, producing hydroperoxy radicals $\mathrm{HO}_{2}$. The dominant chain branching sequence in this temperature range is the series of reactions

$$
\begin{aligned}
& \mathrm{RH}+\mathrm{HO}_{2}=\mathrm{R}+\mathrm{H}_{2} \mathrm{O}_{2} \\
& \mathrm{H}_{2} \mathrm{O}_{2}+\mathrm{M}=\mathrm{OH}+\mathrm{OH}+\mathrm{M}
\end{aligned}
$$

which consumes one radical and produces two $\mathrm{OH}$ radicals. Production of $\mathrm{OH}$ radicals is especially important since $\mathrm{OH}$ reacts rapidly with hydrocarbon fuel molecules. The significant parameter in this system is the activation energy for decomposition of hydrogen peroxide $(-45.5 \mathrm{kcal} / \mathrm{mol})$, or equivalently the strength of the $\mathrm{O}-\mathrm{O}$ bond, which translates into an effective decomposition temperature. Under conditions related to internal combustion engine pressures, this decomposition generally occurs at temperatures of about $900 \mathrm{~K}$. Other reactions that take place at about the same temperature range and involve breaking the same type of $\mathrm{O}-\mathrm{O}$ bond are the decompositions of alkylhydroperoxides, such as

$$
\begin{aligned}
& \mathrm{CH}_{3} \mathrm{OOH}=\mathrm{CH}_{3} \mathrm{O}+\mathrm{OH} \\
& \text { and } \quad \mathrm{nC}_{6} \mathrm{H}_{13} \mathrm{OOH}=\mathrm{C}_{6} \mathrm{H}_{13} \mathrm{O}+\mathrm{OH}
\end{aligned}
$$

Numerical modeling studies of engine knock $[21,22]$ in internal combustion engines indicated that some antiknock additives, including tetraethyl lead, act by 
suppressing this intermediate temperature chain branching reaction sequence. Although tetraethyl lead is no longer used as an antiknock additive in many parts of the world due to its adverse environmental impacts, its mode of effectiveness may provide important insights into the development of future antiknock compounds. The modeling analysis indicated that when tetraethyl lead is added to gasoline, the lead evolves into lead oxide in solid particulate form. These particulates then provide a distributed amount of heterogeneous surface area in the engine end gas where $\mathrm{HO}_{2}$ and other radical species are adsorbed, thereby removing them from the reactive radical pool. An altemative theory proposed by Benson [23] suggests that the role of tetraethyl lead is to provide gas phase, not solid particulate, oxides of lead, which then similarly eliminate $\mathrm{HO}_{2}$ from the reactive radical pool. Each $\mathrm{HO}_{2}$ radical thus removed under these conditions is therefore unable to participate in the chain branching reaction sequence of reactions (13) and (14) and the resulting lower rate of reaction is sufficient to suppress the autoignition of the engine end gases and eliminate knocking. Similarly, additives such as alkylhydroperoxides which decompose at the same conditions where $\mathrm{HO}_{2}$ chain branching is important, accelerate the overall rate of reaction and promote engine knock.

\section{Low Temperature Ignition}

At sufficiently low temperatures, alkyl radicals produced by $\mathrm{H}$ atom abstraction from the fuel react primarily by addition to molecular oxygen via reaction (1) to produce alkylperoxy radicals. The subsequent sequence of reactions has a great wealth of kinetic and thermochemical detail, some of which will be discussed below. However, the overall process includes reactions which lead to chain branching and other sequerices which lead only to chain propagation. A careful and detailed understanding and kinetic description of the rates of these different reaction paths is required to be able to interpret and predict the response of laboratory and applied combustion chemistry problems.

Much of the practical interest in hydrocarbon oxidation under these conditions is motivated by the observation that these conditions are especially important in producing engine knock and ignition in diesel engines. Extensive kinetic analyses of hydrocarbon oxidation under these lower temperature conditions [24] have identified the most important features of these problems. Most models of hydrocarbon autoignition have been motivated by the assumption that the chemical details of hydrocarbon oxidation are so complex that significant simplifications are essential in order to be able to simulate the process. Perhaps most prominent of these simplified model treatments of hydrocarbon ignition are the "Shell Model" [25] and related developments by Keck [26] and Cox and Cole [27]. A recent survey and critical analysis of these simplified approaches by Griffiths [28] has summarized strengths and limitations of these models. However, recent studies in detailed kinetic modeling of hydrocarbon oxidation [22] have made it possible to address a wide variety of issues related to ignition, most of them leading to improved descriptions of ignition in intemal combustion engines and engine knock.

6.1 Negative Temperature Coefficient and Low Temperature Reaction Mechanisms At temperatures lower than approximately $900 \mathrm{~K}$, high activation energies for alkyl radical decomposition make these processes relatively slow. Under such conditions, the most important reactions for alkyl radicals $R$ consist of addition of

$$
\mathrm{R}+\mathrm{O}_{2}=\mathrm{RO}_{2}
$$

molecular oxygen. In many ways this reaction is the most important step for low temperature oxidation, although it does not immediately determine the overall rate of chain branching. The activation energy for reaction (1) is approximately zero in the forward direction and quite large $(-30 \mathrm{kcal} / \mathrm{mol})$ in the dissociation direction. Therefore the equilibrium constant for this reaction is very strongly temperature dependent. At very low temperatures, reaction (1) proceeds rapidly to produce $\mathrm{RO}_{2}$ very efficiently; at high temperatures $\mathrm{RO}_{2}$ dissociates rapidly and the concentration of $\mathrm{RO}_{2}$ is very small. Benson [29] has defined the concept of a "ceiling temperature" in terms of the equilibrium constant for reaction (1), where

$$
\text { [R] }\left[\mathrm{O}_{2}\right] /\left[\mathrm{RO}_{2}\right]=1
$$

and it can often be convenient to think, rather simplistically, that at temperatures below the ceiling temperature, oxidation of alkyl radicals takes place through 
addition of molecular oxygen, and at temperatures above the ceiling temperature, alkyl radicals are consumed by $\beta$-decomposition. As described below, there is a general sequence of reactions which follow the production of $\mathrm{RO}_{2}$ that leads to chain branching which, because of the temperature-dependent equilibrium constant of reaction (1), shuts off above the ceiling temperature. The chain branching reactions that operate above the ceiling temperature do not become fast until the temperature exceeds the ceiling temperature by a considerable amount. As a result, there is a temperature range characterized by a so-called "negative temperature coefficient" (NTC) of reaction, over which the overall rate of fuel oxidation actually decreases as temperature is increased. Eventually, higher temperature chain branching reactions become more important and the rate of reaction again increases with increasing temperature. Below, examples of NTC behavior are described.

The $\mathrm{RO}_{2}$ radicals formed by reaction (1), unless they immediately decompose back to $\mathrm{R}+\mathrm{O}_{2}$, then react primarily through transfer of $\mathrm{H}$ atoms within the radical species. This isomerization process is rather complex and proceeds through a transition state consisting of a ring-like structure which includes all of the atoms between the $\mathrm{H}$ atom being transferred and the $\mathrm{O}-\mathrm{O}$ radical site. The rate of this process depends on the number of atoms in this transition state ring structure and the type of $\mathrm{C}-\mathrm{H}$ bond (i.e., primary, secondary, or tertiary) being broken. This process has been described by Pollard [24] and then used $[22,30,31]$ to simulate this process. Overall, this reaction path is denoted by

$$
\mathrm{RO}_{2}=\mathrm{QOOH}
$$

where $Q$ represents an olefin structure.

The next reaction of these $\mathrm{QOOH}$ radicals really determines the overall chain branching rate of combustion at lower temperatures. There are three classes of reactions which provide chain propagation. The $\mathrm{QOOH}$ radicals

$$
\begin{aligned}
\mathrm{QOOH} & =\text { Heterocycle }+\mathrm{OH} \\
& =\text { Conjugate olefin }+\mathrm{HO} 2 \\
& =\beta \text {-decomposition }
\end{aligned}
$$

can cyclize to produce a range of epoxide or heterocyclic species products. The rate of this process depends on the ring size of these heterocyclic compounds [22,24]. For certain limited types of $\mathrm{QOOH}$ radicals, unimolecular decomposition can lead to olefins or smaller species and oxygenated compounds. All of these product species include one radical, so these reaction sequences which began with one $R$ alkyl radical are effectively chain propagation paths.

A fourth reaction sequence for $\mathrm{QOOH}$ is the addition of another $\mathrm{O}_{2}$ species to produce a $\mathrm{O}_{2} \mathrm{QOOH}$ species. This product can then isomerize further to produce a ketohydroperoxide species which is reasonably stable, in addition to $\mathrm{OH}$ radicals. When the ketohydroperoxide eventually decomposes, it leads to additional radicals and smaller hydrocarbon species. The overall reaction sequence therefore produces two or more radicals along with smaller stable species, providing overall chain branching. The relative rates of each of these elementary processes will establish the chain branching rate at any given temperature and the overall rate of ignition.

\subsection{Stirred Reactor Simulations}

An important class of applications is the stirred reactor. This consists of a reaction volume in which incoming reactants are rapidly and thoroughly mixed with residual gases, and the outflow from the reactor consists of the average contents of the reactor. Computationally, the inlet boundary condition generally consists of a fixed mass flux and composition, while the outflow condition consists of a fixed pressure and zero gradients in the species mass fractions and temperature. In many cases, the reaction takes place at nearly constant temperature. Most model simulations are carried out for steady-state conditions, but time-dependent phenomena can be simulated equally well, which is required for phenomena such as those reported by Lignola et al. [32]. The time-dependent formulation can lead to complex behavior including periodic ignitions, cool flames and other features.

We have used experimental data from a stirred reactor obtained by Dagaut et al. [33] to study the oxidation of n-heptane over a temperature range from $550-1150$ K. Steady-state production of formaldehyde and propionaldehyde are shown as functions of temperature in Fig. 2. The presence of a negative temperature 
coefficient region from about $600-750 \mathrm{~K}$ is evident in both the modeling and experimental results.

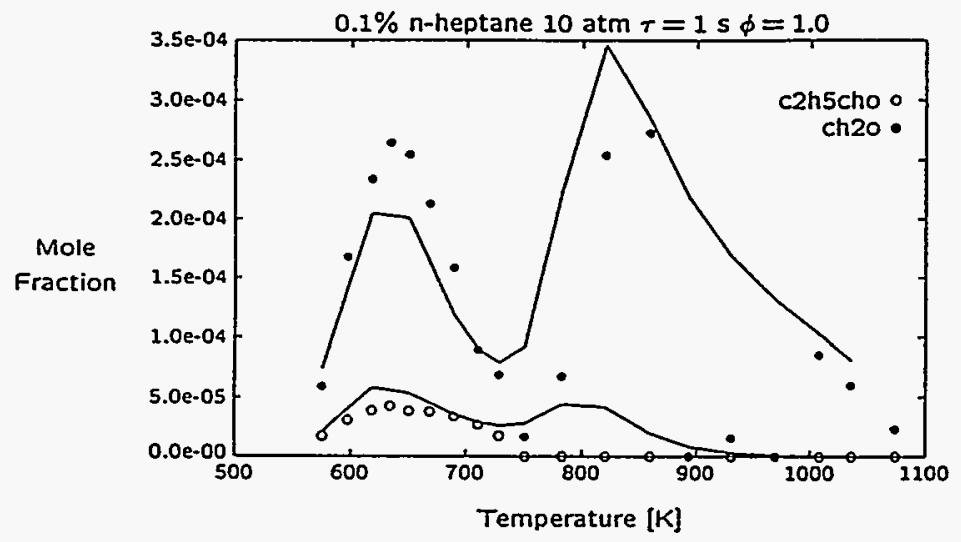

Figure 2. Experimental (circles) and computed concentrations of formaldehyde and propionaldehyde in stirred reactor for $n$-heptane at $10 \mathrm{~atm}$, residence time of $1 \mathrm{sec}$.

\subsection{Rapid Compression Machine}

Many experimental studies have used a system in which a piston is used to compress a reactive mixture to reaction temperatures and pressures. This system resembles a piston engine which operates with only one compression cycle. The boundary conditions are constant mass and volume, with heat transfer at.a rate determined by comparison with measured pressure-time data. In many ways, the rapid compression machine $(R C M)$ is like the shock tube in computational modeling terms, although heat losses in the shock tube are rarely important but can be very significant in RCM simulations. We have examined data from Minetti et al. [34] over temperatures from $650-900 \mathrm{~K}$ for stoichiometric mixtures of n-heptane andoxygen, diluted by nitrogen and argon. Computed temperature histories [35] from simulations of ignition of $n$-heptane are shown in Fig. 3. The results again show a significant NTC behavior. A two-stage ignition is observed for an initial temperature of $650 \mathrm{~K}$, a more rapid two-stage ignition is seen at an initial temperature of $750 \mathrm{~K}$, but then a longer ignition delay time is shown for an initial temperature of $850 \mathrm{~K}$, where the first stage, associated with the low temperature sequence of reactions, has disappeared.

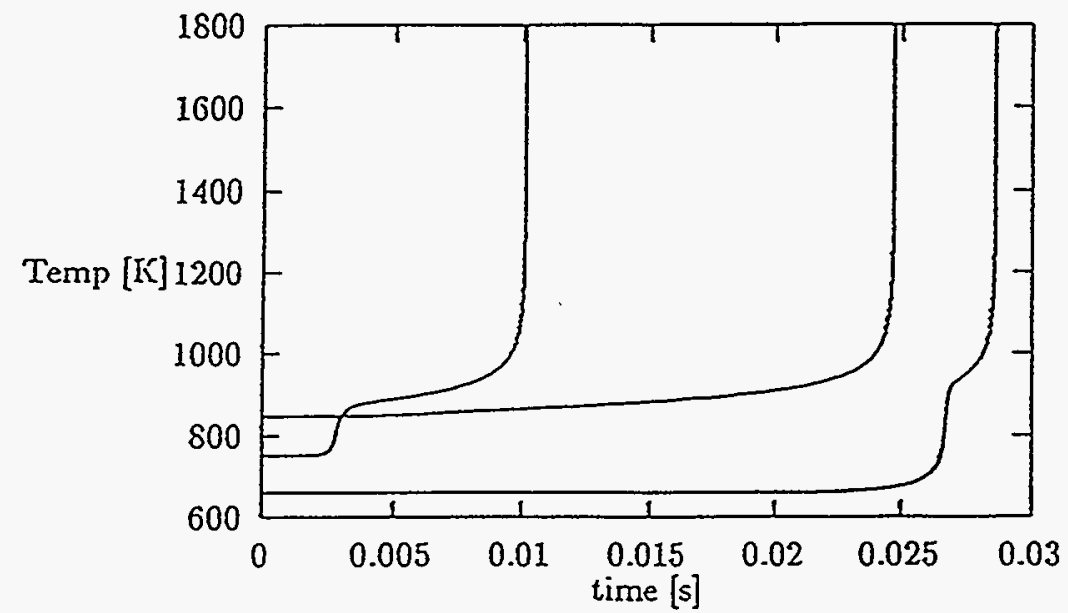

Figure 3. Computed temperature histories in rapid compression machine simulations, stoichiometric n-heptane/oxygen in nitrogen and argon. 


\subsection{Engine Knock}

Perhaps the most dramatic practical example of the importance of low temperature ignition kinetics is the problem of engine knock in spark-ignition engines. Past experimental studies [36] and modeling work [22] have shown how such factors as fuel molecule size and structure influence the onset of engine knock. In a recent study [37] of autoignition kinetics and engine knock, octane ratings and ignition of the five distinct isomers of hexane were studied using motored engine experiments and kinetic modeling. This work showed how $\mathrm{RO}_{2}$ isomerization, decomposition of QOOH species, and production and decomposition of ketohydroperoxides all combine to determine autoignition in internal combustion engines. Modeling engine knock problems requires following the pressure and temperature experienced by engine end gases, conditions which result from piston motion, turbulent flame propagation, and heat transfer with other processes of lesser importance. In real engines, residual product gases from previous engine cycles also contribute to the details of ignition. When all of these factors are included in model calculations, the details of the reaction mechanisms are sufficient to reproduce the influences of fuel molecule structure and size on ignition rates for a very wide range of alkane, olefin and oxygenated fuels. In addition, these models show how fuel blending agents such as methyl-tert butyl ether (MTBE) are effective in suppressing engine knock.

\section{Summary}

Current reaction mechanisms are capable of simulating a wide range of ignition phenomena in both laboratory and practical environments. Each class of problems requires a thorough description of the relevant initial and boundary conditions in order to reproduce the physical problem. Perhaps the most important requirement of each kinetic model is the ability to accurately quantify the reaction sequences leading to chain branching, since ignition is most generally defined as a process in which explosive radical growth leads to rapid fuel consumption and heat release.

\section{Acknowledgments}

The authors thank Prof. Eliseo Ranzi of Politecnico di Milano for support of P. Gaffuri during this work. This work was supported by the DOE Office of Basic Energy Sciences, Chemical Sciences, and was carried out under the auspices of the U. S. Department of Energy by the Lawrence Livermore National Laboratory under contract W-7405-ENG-48.

\section{References}

1. Glassman, I., Combustion, Academic Press, Inc., Orlando, Fla., 1987.

2. Westbrook, C. K., and Dryer, F. L., Eighteenth Symposium (International) on Combustion, p. 749, The Combustion Institute, Pittsburgh, 1981.

3. Westbrook, C. K., and Dryer, F. L., Prog. Energy Combust. Sci. 10, 1 (1984).

4. Baulch, D. L., Cobos, C. J., Cox, R. A., Esser, C., Frank, P., Just, Th., Kerr, J. A., Pilling, M. J., Troe, J., Walker, R. W., and Warnatz, J., J. Phys. Chem.

- Ref. Data 21, 411-734 (1992).

5. Warnatz, J., Combustion Chemistry, W. C. Gardiner, Jr., ed., ch. 5, "Rate Coefficients in the C/H/O System," Springer-Verlag, New York, 1984.

6. Miller, J. A., and Bowman, C. T., Prog. Energy Combust. Sci. 15, 287(1989).

7. Glarborg, P., Miller, J. A., and Kee, R. J., Combust. Flame 65, 177 (1986).

8. Dagaut, P., Reuillon, M., Boettner, J.-C., and Cathonnet, M., Twenty-Fifth Symposium (International) on Combustion, p. 919, The Combustion Institute, Pittsburgh, 1995.

9. Tieszen, S. R., Stamps, D. W., Westbrook, C. K., and Pitz, W. J., Combust. Flame 84, 376-390 (1991).

10. Westbrook, C. K., and Dryer, F. L., Combust. Flame 37, 171-192 (1980).

11. Burcat, A., Scheller, K., and Scheller, K., Combust. Flame 16, 29 (1971).

12. Westbrook, C. K., and Pitz, W. J., Shock Waves and Shock Tubes, Bershader and Hanson, eds., Stanford Univ. Press, 1986.

13. Oran, E. S., Boris, J. P., and Kailasanath, K., Numerical Approaches to Combustion Modeling, p, 421, AIAA, Washington, 1991.

14. Westbrook, C. K., Combust. Flame 46, 191-210 (1982).

15. Westbrook, C. K., Nineteenth Symposium (International) on Combustion, p. 127, The Combustion Institute, Pittsburgh, 1982. 
16. Bodenstein, M., and Lind, S. C., Z. Physik. Chem. 57, 168 (1906).

17. Westbrook, C. K., Combust. Sci. Technol. 23, 191-202 (1980).

18. Keller, J. O., and Westbrook, C. K., Twenty-First Symposium (Intemational) on Combustion, p. 547, The Combustion Institute, Pitusburgh, 1986.

19. Keller , J. O.,Bramlette, T. T., Dec, J. E., and Westbrook, C. K., Combust. Flame 79, 151 (1990).

20. Barr, P. K., Keller, J. O., Bramlette, T. T., Westbrook, C. K., and Dec, J. E., Combust. Flame 82, 252-269 (1990).

21. Pitz, W. J., and Westbrook, C. K., Combust. Flame 63, 113-133 (1986).

22. Westbrook, C. K., Pitz, W. J., and Leppard, W. R., Society of Automotive Engineers, SAE-912314 (1991).

23. Benson, S. W., J. Phys. Chem. 92, 1531-1533 (1988).

24. Pollard, R. T., Hydrocarbons, ch. 2, Comprehensive Chemical Kinetics, vol. 17, Gas-Phase Combustion, (C. H. Bamford and C. F. H. Tipper, eds.), Elsevier, New York, 1977.

25. Halstead, M. P., Kirsch, L. J., and Quinn, C. P., Combust. Sci. Technol. 30, 45-60 (1977).

26. Hu, H., and Keck, J. C., Society of Automotive Engineers Trans. 96, 1987.

27. Cox, R. A., and Cole, J. A., Combust. Flame 60, 109 (1985).

28. Griffiths, J. F., Prog. Energy Combust. Sci. 21, 25-107 (1995).

29. Benson, S. W., Prog. Energy Combust. Sci. 7, 125 (1981).

30. Westbrook, C. K., Warnatz, J., and Pitz, W. J., Twenty-Second Symposium (International) on Combustion, p. 893, The Combustion Institute, Pittsburgh, 1988.

31. Chevalier, C., Pitz, W. J., Warnatz, J., Westbrook, C. K., and Melenk, H., Twenty-Fourth Symposium (International) on Combustion, p. 93, The Combustion Institute, 1992.

32. Lignola, P.-G., Reverchon, E., Autuori, R., Insola, A., and Silvestre, A. M., Combust. Sci. Technol. 44, 1-14 (1985).

33. Dagaut, P., Reuillon, M., and Cathonnet, M., Combust. Sci. Technol. 95, 233 (1994).

34. Minetti, R., Carlier, M., Rivaucour, M., Therssen, E., and Sochet, L.-R., Combust. Flame, in press (1995).

35. Gaffuri, P., Curran, H. J., Pitz, W. J., and Westbrook, C. K., Combustion Institute Central and Western States Section Proceedings, 263 (1995).

36. Lovell, W. G., Ind. Eng. Chem. 40, 2388 (1948).

37. Curran, H. J., Gaffuri, P., Pitz, W. J., Westbrook, C. K., and Leppard, W. R., Society of Automotive Engineers, to be published (1995). 

Technical Information Department - Lawrence Livermore National Laboratory University of California - Livermore, California 94551

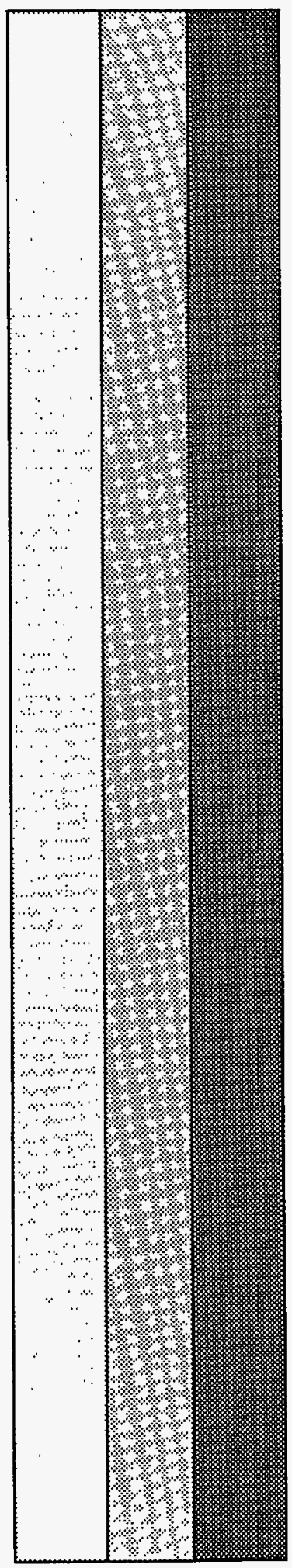

